\title{
AN nD MODELLING APPROACH TO IMPROVED COMMUNICATION PROCESSES FOR CONSTRUCTION
}

\author{
A.J. MARSHALL-PONTING \& G. AOUAD \\ School of Construction \& Property Management, University of Salford, Bridgewater \\ Building, Salford, M7 1NU, UK.
}

\begin{abstract}
.
The number and variety of design and construction stakeholders can make effective and efficient collaboration difficult, a situation that is not helped by the sequential way in which many of the processes work. This paper presents the findings of a number of workshops focussing on the problems and barriers inherent in the industry which would currently prevent effective implementation of a process improvement tool. Discussion attempts to illustrate the ways in which the concurrent approach that $n D$ Modelling is taking can help overcome the most significant of these problems. It is concluded that an $\mathrm{nD}$ model could provide the greatest value as a communication tool for industry and education as education arguably provides one of the greatest opportunities by which improvements to the industry may come about.
\end{abstract}

\section{Introduction}

With the business lifecycle of the construction industry being characterised by so many professionals and stakeholders, there are massive gains to be made by companies able to integrate all the stakeholder requirements into a mutually equitable solution. But collaboration is difficult due to the constraints and conflicts upon practitioners and researchers imposed by the number and variety of social, economic and legislative factors, different epistemological backgrounds and methods, and the personal requirements and agendas of other interested stakeholder groups.

Information communication technologies (ICTs) may help facilitate a solution, but with so many conflicts and constraints it is important to identify the end user groups and their requirements. The literature describes some of the advantages and disadvantages that information systems can have which may help overcome the industry's problems, as identified in a number of workshops held by the $\mathrm{nD}$ Modelling project. An $\mathrm{nD}$ model has been defined as "an extension of the building information model, which incorporates multiaspects of design information required at each stage of the lifecycle of a building facility" (Lee et al, 2003 p37). The workshop findings show support for the concurrent engineering/nD approach and for the $\mathrm{nD}$ tool being proposed as a means of overcoming some of these problems, but they also demonstrate why successful implementation may be difficult.

\subsection{INFORMATION SYSTEMS DEVELOPMENTS}

In their classic paper, Kiesler et al (1984) argued that although "no one can predict in any detail the nature of the transformations that computers will bring...one aspect of life that will certainly be affected is communication." Even in the early 1980s, it was observed that communication tools such as e-mail, bulletin boards and simultaneous computer conferences were advancing, in the words of Stockton (1981), "like an avalanche." Most discussions at that time focused upon the advantages of computer mediated communication (CMC) for work - fast and precise information exchange, increased participation in problem solving and decision-making, and reduction of 'irrelevant' status and prestige differences (Lancaster 1978; Linstone \& Turoff 1975; Martino 1972). But they also expected that there would be more complex and potentially negative implications - changes to status relations and organisational hierarchies, and difficulties resolving conflicts as a result of rapid, textual communication. This is illustrated by the expectation that: "The scientific literature will become unified...Scientists everywhere will have equal access...the advantage of being in a 
famous center of research will be substantially lessened. Scientists in obscure universities...will be able to participate in scientific discourse more readily" (Folk, 1977).

The question of how computers are changing our lives has fuelled huge debate: visionaries believe an information revolution is now in our midst whereby new opportunities, enabled by emerging technologies such as hypermedia, AI and VR, will allow people to create and develop intellectually in innovative and exciting ways. In relation to evaluating this IT-job impact, theorists have sought to identify the process by which benefits or problems emerge. Two main theories have emerged:

1. technical determinists believe technology is the single most important factor in determining an organisation's success and investing in technology is considered the only way to survive - notion of 'being left behind,'

2. the social action approach proposes technology is enabling rather than deterministic. It is the strategic choices, made by management, as to how technology is to be used that determine how the organisation is structured. So organisational changes are assumed caused by managers' decisions and IT adoption may be one resource of many.

In reality, it is likely to a mixture of both technology and decisions that bring about change; this was found to be the case in a diverse range of industries in Scotland (Buchanan \& Boddy, 1983).

The term 'groupware' was coined in 1978 by Johnson-Lenz \& Johnson-Lenz (1980) who defined it as "intentional group processes plus software to support them." This emphasises both the software and the group processes and its specific aim of being designed to enhance that group process and consequently its productivity. Such systems include group support systems, computer-supported cooperative work (CSCW), group decision-support systems (GDSS) and computer-mediated communication. Pendergast \& Hayne (1999 p311) argue groupware should NOT be defined loosely as any networked application that allows individuals to share data.

\subsection{EXPECTED COMMUNICATION OUTCOMES}

Kiesler et al argue (1984) that it may not be desirable to aim for improved communication and participation at all times as equal participation, objectivity and efficiency sometimes interfere with important group outcomes. Therefore to be effective group members may need to organise themselves in a number of ways, e.g. develop affective bonds, a status distribution to help sort multiple objectives and a hierarchy to determine influence. To accomplish these purposes, social structures provided by roles, norms, and status and reinforced by trust and personal engagement with others is critical.

Technical problem solving computer-mediated groups might be "disorganized, democratic, unrestrained, and perhaps more creative than groups communicating more traditionally; they might have trouble reaching consensus if the "correct" answer is not obvious; they might not act as cool, fast decision makers" (Kiesler et al, 1984). In their study comparing group processes in three contexts - face to face and anonymous and nonanonymous computer use - they found computer-mediated groups took longer to reach consensus, exchanged fewer remarks (controlling for technical and typing differences) but that there was more equal participation, and higher decision choice shift and use of extreme positions. When using computers for communication it is important to establish the desired outcomes: Pendergast \& Hayne (1999) argue that when multiple users work together, rich but potentially unexpected interactions occur and due to individual goals and experience levels, the potential for uncertainty and unpredictability increases. One of the benefits of group decision support systems (GDSS) and one huge difference between a GDSS and a face-toface meeting is that technology can provide the option for group members to contribute comments or messages anonymously and there is much research to support the increases in production and satisfaction when brainstorming is done anonymously (Pendergast \& Hayne, 
1999). Anonymity doesn't affect the ability to contribute, but it does seem to affect what a participant is prepared to say and how. Therefore CMC conditions might be useful for brainstorming activities, especially with under-represented or minority groups. Outcomes may also depend on the existing relationships: if members are discontented and in conflict with one another, computer-mediated behaviour exacerbates aggressiveness and polarises members; in cooperative groups impersonal behaviour may encourage joint approaches to working and reduce self-consciousness e.g. students were more willing to approach a professor for assignment assistance or potential date through e-mail than face-to-face encounters (Welsch, 1982).

As misunderstandings can easily occur in multi-party CMC conditions, there is still a high requirement for the social protocols used within face to face meetings to facilitate effective co-ordination, e.g. a pre-set agendas, hand-raising, the chairman (Novick \& Walpole, 1990). Communication can also be enhanced by the type or 'shape' of the network: in a classic social psychology experiment, Leavitt (1951) found a 'wheel' arrangement, with communication being focussed through a central spokesperson, was the most efficient set-up, and made the least errors. However, group differences disappear if they are allowed enough time to organise themselves (Guetzkow \& Simon, 1955) into a self-selected structure best suited to the problem.

\subsection{THE CONCURRENT ENGINEERING vs. SEQUENTIAL APPROACH}

The traditional and incremental design processes are inefficient. The sequential 'over-thewall' approach is problematic as it allows information wastage, loss and repetition, and long lead times as the changes to the design are made and passed on to the next professional for their updates. The problems of traditional, sequential product development include: "an ineffective internal customer-supplier-relationship" due to the lack of involvement of other involved departments (Brödner, 1996); the uncompetitiveness e.g. of European products compared to Far Eastern products which were cheaper and qualitatively better (Womack, Jones \& Roos, 1990); the lack of provision of factors beyond production, marketing and service required for providing value to the product development chain (Syan, 1994); redundant and replicated work at different interfaces between departments (Müller, 1987); and slow product development and process implementation (Buggert, 1995).

Concurrent Engineering is a work organisational concept that aims to increase effectiveness and efficiency of product development through integrated and temporally parallel, as opposed to sequential, product and process development (Durst \& Kabel, 2001). Similar definitions emphasise the inclusion of customers and their expectations, and the holistic approach:

"Concurrent Engineering is a systematic approach to the integrated, concurrent design of products and their related processes, including manufacture and support. This approach is intended to cause the developers, from the outset, to consider all elements of the product life cycle from concept through disposal, including quality, cost, schedule, and user requirements." (Winner et al, 1988, cited in CIB website)

\subsubsection{The $n D$ modelling approach}

The From 3D to nD Modelling project favours a holistic approach whereby the computerised design is 'central' to the professionals who can view it and make their changes at any point in time. This EPSRC funded platform grant has made a number of the design, construction and maintenance dimensions explicit and aims to integrate discrete knowledge advancements made within time, cost, accessibility, crime, sustainability, acoustics, thermal and visual comfort, buildability and maintainability into a holistic decision-making tool.

The technical nature, detail and sheer volume of the information that is involved in many of the processes often means that specialist skills or training are required to efficiently and 
effectively interact with them. When building and renovation plans are used in public forums, for example for urban regeneration, the lack of such experience means certain societal groups may become excluded from participating in the decisions affecting them. ICTs can play an important role in speeding up and improving various processes. For these reasons, it was decided that an $\mathrm{nD}$ solution should take the form of a computer model which would allow 'what-if' analyses to be performed: that is to say, what are the knock-on effects for time, cost, maintainability etc of widening a door to allow for wheelchair access? Employing 3D visualisations of the proposed designs would allow them to be more easily understood than more traditional 2D plans or any other methods.

\subsection{2. $n D$ Modelling \& Concurrent Engineering}

Without consciously aiming to implement a CE framework, nD Modelling adopted a number of its most prominent characteristics:

- Durst \& Kabel (2001) emphasise that "in CE technical, organizational, social and personnel aspects are interconnected".

- The attached philosophy is that "formerly used sequential processes can be carried out temporally parallel or overlapped, or even fully integrated i.e. summarized as one activity" (Eversheim, 1995).

- "The concept of Concurrent Engineering strives to include all concerned areas of the product life cycle, from conception to design, production and eventually waste disposal" (Luczak, 1998)

- Pennell \& Winner (1989) argue the targets of CE are associated primarily with: a reduction of product development time, by simultaneously; improving the product quality and; reducing production costs. Like nD, Durst \& Kabel (2001) argue these goals could be obtained by 'an improved consideration of requirements between the different departments involved in the product development process'. Additionally, "activities to coordinate processes and the transfer of information in the process should be started as early as possible." (Stahl et al, 1997)

\section{Research findings}

\subsection{ACADEMIC WORKSHOP 2}

This workshop aimed, through the provision of a case study scenario, to obtain discipline specific knowledge and start to establish what some of the similarities and conflicts in these design requirements would be. The task required the nine individuals to add improvements based on their specialist knowledge to a general design for a space for ten researchers. From the diagrams and presentations, a table was drawn up showing the features each individual identified. A total of 46 design features were identified, although the total number mentioned by each specialist ranged from 6 to 17, with an average of 10 features. It would be difficult to represent some of the features in a computer model, especially those which are social or intangible in nature e.g. 'changing trends'. Of more relevance to decision-making though, were the issues which caused conflicts within the design and some of these are more apparent from the table than others (see Marshall-Ponting \& Aouad, 2003 for more details).

\subsection{NATIONAL WORKSHOP}

The purpose of this workshop was to take the $\mathrm{nD}$ vision developed so far to a national forum to gain support for it and its approaches and to ensure that these were in line with the demands and requirements of the wider academic and UK industrial communities. These aims were to be achieved by asking the group to discuss three questions: "How may IT support integrated design and construction in the future?" (in both 5 and 20 years time) and 
"What are the barriers and opportunities for implementation?" The findings were classified into people, process and technology issues and the opportunities findings have been represented by a mind map diagram - see figure 1 below.

The responses to question one included issues relating to barriers, drivers, standards, culture change and systems but much of the time was spent by the groups trying to establish where the industry was currently. This difficulty was typified by statements like "...the industry is fragmented and characterised by one-off relationships, a poor flow of information, the designing in of problems, an increasing litigation culture, there is massive wastage (30\% of materials)" and "...industry has high levels of wastage and fragmentation, a lack of value and investment in R\&D and poor information flows." Much discussion also focussed upon the systems required to support integrated design and construction and whilst it was established that some organisations are already using computer modelling, few are doing so in an efficient and effective manner. The features deemed desirable in a system included simplicity, interoperability and ease of use for all and some of the quotes include "...this would be transferred through visualisation, as $98 \%$ of the industry cannot understand drawings" and "...IT skills are lacking and so more education and training is required."

For the 20 year period, the most common theme was data or information needs and the systems required to support them. As far as communication and educational applications are concerned, one of the most features would be that the system would be symbiotic with individual's working and learning styles to enable continual organisational learning: "...a radical shift is needed, not incremental and continuous re-working, which would restructure the industry so that it would be right the first time on the site." The two other major themes which emerged were the drivers for change - the desire to demonstrate construction cost savings and better flexibility for a more diverse industry and outputs - and a change to the philosophical approach to allow a greater emphasis upon process and culture change and less upon technology.

The final question asked participants to determine the barriers and opportunities for implementation of an $\mathrm{nD}$ tool. The greatest barrier was identified as the industry's structure which accounted for $31 \%$ of the responses and included its short-termism, lack of trust and adversarial nature. It was also argued that the systems - and not just IT systems - seem to get in the way of effective working. The key issues include:

- Lack of trust

- Lack of project team continuity

- Inadequate training \& education
- Intellectual property

- Lack of institutional memory

- Lack of knowledge transfer

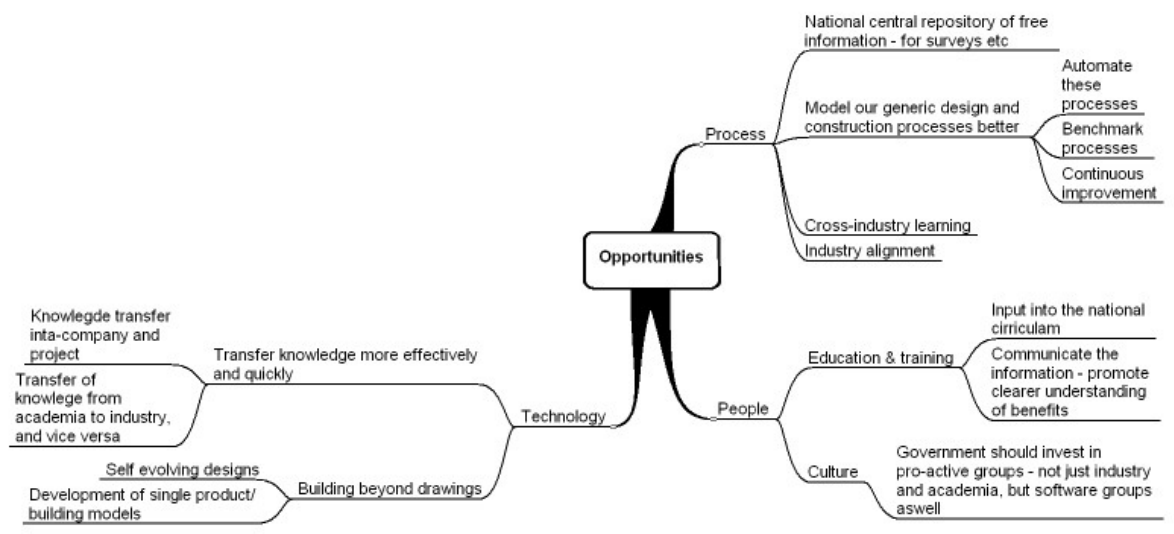

Figure 1. National workshop response: 'The potential opportunities for $\mathrm{nD}$ industry implementation' 
The greatest opportunity was thought to be in knowledge capture, utilisation and transfer (without data loss). Knowledge-related suggestions - see figure 1 - included the development of a free national registry for information and it was thought that this would help to develop a knowledge sharing culture. Education and training was also identified as an opportunity and some quotes which illustrate this include: “...building beyond drawings there are elements which are not captured on the drawing itself (only $80 \%$ on drawings)" and "...information communication; learning."

\subsection{INTERNATIONAL WORKSHOP}

This was concerned with validating the vision on an international scale and thinking about how it would be implemented. The most relevant findings for this paper are shown in figure 2 below. It can be seen that the biggest challenges facing $\mathrm{nD}$-enabled construction should be addressed, Lee et al argue (2003 p29) through research initiatives, but that education and culture, and implementation/integration have been rated as the most important.

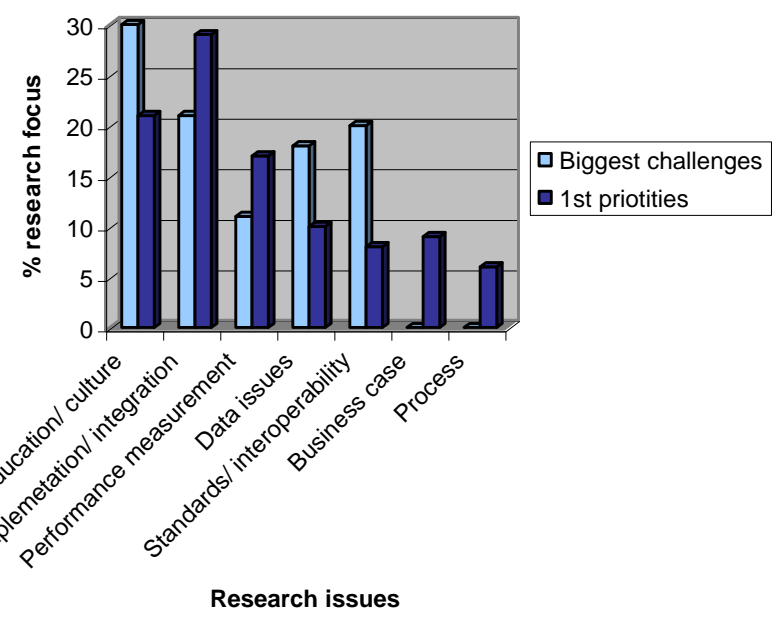

Figure 2. International workshop: Bar chart showing the biggest challenges \& first priorities for $\mathrm{nD}$-enabled construction

\section{Discussion}

The purpose of this paper was to look at the findings of the $\mathrm{nD}$ workshops held to date and establish how the construction industry's communication processes in particular could benefit from an $\mathrm{nD}$ tool. Although it was not possible for all the design and construction professionals to complete the scenario exercise, with a total number of 46 design features mentioned and for only nine individuals this demonstrated the volume of relevant information. The value of an $\mathrm{nD}$ tool would then be its ability to represent and manipulate large volumes and different types of information quickly, although it is expected that some features would be more amenable to quantification and visualisation than others. This is illustrated by a conference question posed of how we could integrate fun and enjoyment into the model.

The usefulness of this workshop lay, not in minute details of how things should be designed, but in the exercise's ability to get the relevant individuals thinking about the limitations of their own discipline and about the problems from another perspective. This point was supported by the finding that even the most accepted of general design features, such as the use of a porch area and internal doors, can provide problems for some societal groups. This highlighted the need to think more holistically about the other stakeholder requirements and the value of an $\mathrm{nD}$ building visualisation model would be in its 
ability to show how design suggestions can cause these conflicts. Ideally it would help develop trans-disciplinary thinking in design and construction professionals, thus allowing the sequential updating need to be removed.

In response to the first national workshop question, a lot of concern was shown about the problems of the construction industry and these were focussed primarily on its structure. Much of this discussion time was spent just trying to characterise the industry now and this may have caused problems because of the number of stakeholders involved and their own individual views of the industry and its processes. This opinion may be supported by the statements that the industry is viewed to be fragmented and its information flows are poor. This theme continued to have salience when asked to consider the 20 year period and the barriers to implementation: the industry's structure - short-termism, adversarial nature - was deemed to be the biggest barrier to implementation. This is the area in which an $\mathrm{nD}$ tool could have the greatest impacts though. The technology issues sub-group identified that IT could provide a central store of product information, standard solutions and best practice, and this data would be accessible and editable by all and on demand.

Suggestions for data to be represented in VR models would help decision-making and the use of a single such model would help to remove the major problem of sequential updates. The use of a repository would mean that information, which may be disregarded when projects fail to go ahead, would be retained for use in the future. This way, the problems of continuity and short-termism are reduced and this may be able to have an impact upon the materials wastage problem, which was put at 30\%. The use of VR technology was also deemed important for access and educational reasons as it was stated that $98 \%$ of the industry cannot understand drawings.

Data and information needs and the systems to support these were seen to be the most important theme for the industry in the 20 year time period, but it was thought that for educational applications these systems would have to be easy to use and symbiotic with individual's learning styles. For such systems to be applied usefully within industry, a radical shift in thinking would be needed and subsequent changes within the industry so that designs could be correct in the first instance. Education could help both demonstrate the value of such changes in philosophy in practical real terms and this was identified as a significant opportunity - see figure 1 - but also as the biggest challenge and one of the first priorities for the industry by the international workshop delegates (see figure 2). It was argued that there already are people in industry using computer modelling and so the concepts must work in practice, but the fact that there are few that are doing this in efficient and effective enough ways means that education has a massive role in helping the industry realise the benefits.

Some of the argued benefits of computer-mediated communication include the decrease in status differences, the increased participation in decision-making and the equalised access to information by all. These are all highly important features which an $\mathrm{nD}$ system applied to urban regeneration and education should strive to have. There are further improvements is this system is able to employ a VR interface through which all the $\mathrm{n}$ dimensions identified could be visualised. This increases access to construction plans, most importantly by nonprofessionals which means it is more inclusive, but also allows greater interaction and consequently innovation by those participating in these group processes. However, as pointed out by Kiesler et al (1984) it would be important to properly manage these systems and the expectations of stakeholders using them as improved communication and participation at all times may get in the way of effective planning, especially with urban planning and regeneration. This highlights the question of what the $\mathrm{nD}$ system would be used for and ties in with the findings by Pendergast and Hayne (1999 p313) that using such systems anonymously can have great benefits for brainstorming and innovation activities as the potential for uncertainty and unpredictability increases.

As established by Leavitt (1951) and subsequently supported by other CMC and CE studies, the configuration of the communication channels is important if this is to be both 
effective and efficient. It is for these reasons that the $\mathrm{nD}$ model is located as the central point through which design and construction professionals communicate their specialist requirements. As mentioned in section 1.4.2 there are a number of similarities between the $\mathrm{CE}$ framework and the project features of $\mathrm{nD}$ modelling, not least the multidiscipline product development team who are professionals from various departments in the company and representatives of strategic suppliers and customers (Starbek, Kušar \& Jenko, 1988; ibid 1999). As supported by the findings above that argue for important changes to the industry's structure, "the implementation of Concurrent Engineering must change the whole organisation", it is not something which can be implemented in a piecemeal fashion and favouring incremental changes, but which requires a holistic and inter-disciplinary approach to thinking about the construction processes, as argued in Marshall-Ponting, Aouad \& Curwell (2003) and Marshall-Ponting et al (2002).

\section{Conclusions}

The aim of this paper was to establish how an $\mathrm{nD}$ tool might help improve processes in the design and construction industry, based on the perceived problems as identified in a number of workshops. The major benefit has been to help communication and this could be done on a number of levels. By using a VR interface, it would be possible to communicate designs to a wider audience who would require little if any specialist technical knowledge to understand and use them as a discussion point for improvements or changes in a decision-making forum. Communication using this method would also enhance understanding of the numerous stakeholder viewpoints and help to develop a more holistic approach to design and construction. This could have implications for education, in both the classroom and on-site by professionals working in the field. Communication could also transcend projects: used as an information repository, it could help provide continuity between projects and reduce the short-termism and information loss that is currently a problematic feature of the industry. In conclusion and in answer to the conference question of who the $\mathrm{nD}$ tool is aimed at, the answer is any design and construction practitioner, researcher or educator. An ethical point must be made though this tool is not aiming, through its holistic approach, to replace all these specialists and their knowledge, but to facilitate and improve the ways in which they collaborate and communicate.

\section{References}

Brödner, P.: 1996, Erfolgsfaktor produktentwicklung: Bericht aus einem industriearbeitskreis [Success factor product development], in $\mathrm{P}$. Brödner and $\mathrm{H}$. Paul (eds), Kooperative konstruktion und entwicklung: Nutzungsperspektiven [Cooperative design and development: Perspectives of CAD systems], pp17-38. Mering, Hamp, Muenchen.

Buchanan, D.A. and Boddy, D.: 1983, Organizations in the computer age, Gower, Hampshire.

Buggert, W. and Weilpuetz, A.: 1995, Target costing: Grundlagen und umsetzung des zielkosten-managements [Target costing: Basis and transfer of target costing management], Hanser Verlag, München.

CIB website for The 2nd International Conference on Concurrent Engineering in Construction - CEC99: http://cic.vtt.fi/cec99/index.html\#top Accessed 7th March 2003

Durst, R. \& Kabel, K.: 2001, Cross-functional teams in a concurrent engineering environment - principles, model, and methods, in M.M. Beyerlein, D.A. Johnson, and S.T. Beyerlein, (eds), Virtual Teams, JAI, Oxford, pp. $167-214$.

Eversheim, W.: 1995, Simultanaeous engineering: Erfahrungen aus der industrie für die industrie [Concurrent engineering: experiences from the industry], Springer, Berlin.

Folk, H.: 1977, The impact of computers on book and journal publication. In J.L. Divilbiss (ed) The economics of library automation: Proceedings of the 1976 clinic on library applications of data processing, pp 72-82. University of Illinois Graduate School of Science, Urbana, Illinois.

Guetzkow, H. and Simon, H.A.: 1955, The impact of certain communication nets upon organization and performance in task-oriented groups, Management Science, 1, 233-250.

Johnson-Lenz, P. and Johnson Lenz, T.: 1980, Groupware: the emerging art of orchestrating collective intelligence, presented at the World Future Society's First Global Conference on the Future, Toronto, Canada. 


\section{AN nD MODELLING APPROACH TO IMPROVED COMMUNICATION PROCESSES FOR CONSTRUCTION}

Kiesler, S., Siegel, J and McGuire, T.W.: 1984, Social Pyschological Aspects of Computer-Mediated Communication, American Psychologist, 39, 1123-34.

Lancaster, F.W.: 1978, Toward paperless information systems, Academic Press, New York.

Leavitt, H.J.: 1951, Some effects of certain communication patterns on group performance, Journal of abnormal and social psychology, 46, 38-50.

Lee, A., Marshall-Ponting, A.J., Aouad, G., Wu, S., Koh, I., Fu, C., Cooper, R., Betts, M., Kagioglou, M. and Fischer, M.: 2003, Developing a vision of nD-enabled construction, Construct IT Report, ISBN: 1-900491-923

Linstone, H.A. and Turoff, M. (eds): 1975, The Delphi method: techniques and applications, Addison-Wesley, Reading, Massachusettes.

Luczak, H.: 1998, Arbeitswissenschaft [Industrial engineering and economics] (2nd ed), Springer, Berlin.

Marshall-Ponting, A.J. and Aouad, G.: 2003, Defining a vision for nD-enabled construction. Proceedings of the 3rd International Postgraduate Conference in the Built \& Human Environment, pp783-95. ESAI, Lisbon, Portugal, 3rd-4th April 2003.

Marshall-Ponting, A.J., Aouad, G. \& Curwell, S.: 2003, Supporting construction decision-making with IT - some multi-disciplinary collaboration problems. Proceedings of the CIB W78 Conference - Building Education \& Research (BEAR), 3, pp1466-1479. Salford Quays, Salford, UK, 8-11th April, 2003. ISBN: 1-900491-90-7

Marshall-Ponting, A., Lee, A., Betts, M., Aouad, G., Cooper, R. \& Sexton, M.: 2002, Information Technology Support to Improved Construction Processes: Inter-Disciplinarity in Research and Practice. Paper presented at the Advances in Building Technology Conference, Hong Kong, 4th-6th December 2002.

Martino, J.P.: 1972, Technological forecasting for decisionmaking, American Elsevier, New York.

Müller, K.: 1987, Management für Ingenieure - Grundlagen, Techniken, Instrumente [Management for engineers: Basises, techniques, insruments], Springer-Verlag, Berlin.

Novick, D.G and Walpole, J.: 1990, Enhancing the efficiency of multiparty interaction through computer mediation, Interacting with computers, 2, 229-246.

Pendergast, M. and Hayne, S.: 1999, Groupware and social networks: will life ever be the same again? Information \& Software Technology, 41, 311-318.

Pennell, J. and Winner, R.: 1989, Concurrent engineering: Practices and prospects, in GLOBECOM 89 IEEE Global Telecommunications Conference and Exhibition for the 1990s and Beyond, pp647-655, 27-30th November 1989, Dallas, Texas.

Stahl, J., Luczak, H., Langen, R., Weck, M., Klonaris, P. and Pfeifer, T.: 1997, Concurrent engineering of work and production systems, European Journal of Operations Research, 100, 379-398.

Stockton, W.: 1981, The technology race, New York Times Magazine, $28^{\text {th }}$ June 1981.

Syan, C. and Mennon, U.: 1994, Concurrent engineering: Concepts, implementation and practice, Chapman \& Hall, London.

Welsch, L.A.: 1982, Using electronic mail as a teaching tool, Communications of the ACM, 23, 105-108.

Womack, J.P., Jones, D.T. and Roos, D.: 1990, The machine that changed the world, Rawson, New York. 